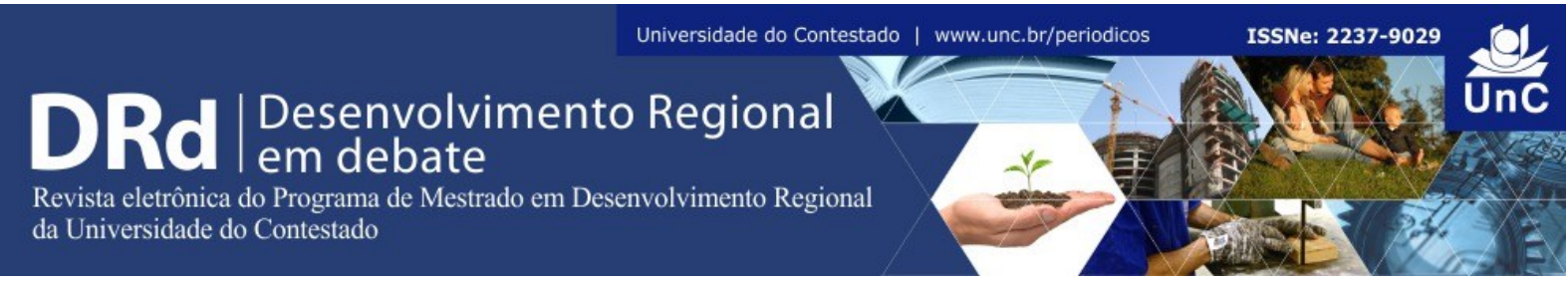

\title{
A ERVA-MATE NO PLANALTO NORTE CATARINENSE: OS COMPOSTOS BIOATIVOS COMO VARIÁVEL NA DETERMINAÇÃO DAS ESPECIFICIDADES NECESSÁRIAS AO RECONHECIMENTO COMO INDICAÇÃO GEOGRÁFICA
}

\author{
Damaris Aparecida de Cassia Krul Pires ${ }^{1}$ \\ Daniela Pedrassani ${ }^{2}$ \\ Valdir Roque Dallabrida ${ }^{3}$ \\ Eliziane Luiza Benedetti ${ }^{4}$
}

\begin{abstract}
RESUMO
Historicamente, a erva-mate (Ilex paraguariensis) tem sido um dos principais produtos agrícolas da região sul do Brasil e, atualmente, representa espécie de grande potencial econômico, social e ecológico. Há evidências do seu benefício à saúde, sendo seus efeitos atribuídos aos compostos bioativos, cuja concentração pode modificar dependendo de variáveis genéticas, ambientais e tecnológicas, incluindo o cultivo e processamento. Desta forma, espera-se que as especificidades dos ervais possam ser um subsídio justificável, como forma de agregação de valor da matéria-prima e valorização dos recursos naturais, e que possa contribuir para o reconhecimento do produto como Indicação Geográfica (IG). Características da erva-mate possibilitam seu cultivo tanto a pleno sol quanto em sombreamento, e em muitos casos a adubação é recomendada. Assim, o objetivo deste estudo foi avaliar a influência da luminosidade e da adubação orgânica no teor de cafeína e metilxantinas em folhas de ervamate, desenvolvido em erval em mata, erval em caíva e erval em caíva aberta, no município de Irineópolis-SC. Verificou-se que as plantas em locais de menor luminosidade apresentaram maiores teores médios de cafeína $(12,63 \mathrm{mg} / \mathrm{g} \pm 4,59)$ em comparação as plantas de erval em caíva aberta $(9,46 \mathrm{mg} / \mathrm{g} \pm 2,05)$. Os resultados demonstram que a adição de adubação orgânica, de maneira geral, aumentou os teores de compostos fenólicos e de metilxantinas. Desta forma, o manejo de adubação deve ser considerado para produção de matéria-prima específica, com maior ou menor teor, e possibilitar a produção de matéria-prima diferenciada, conforme exigências do mercado consumidor, e podendo ser uma variável do produto como IG.
\end{abstract}

Palavras-chave: Erva-mate. Adubação. Fenólicos. Metilxantinas. Indicação Geográfica.

\footnotetext{
${ }^{1}$ Farmacêutica, Mestranda do Programa de Mestrado em Desenvolvimento Regional da Universidade do Contestado (UnC). Santa Catarina. Brasil. E-mail: damafarma@hotmail.com

${ }^{2}$ Doutora em Medicina Veterinária e docente do Programa de Mestrado em Desenvolvimento Regional da UnC. Santa Catarina. Brasil. E-mail: daniela@unc.br

${ }^{3}$ Geógrafo, Doutor em Desenvolvimento Regional e docente do Programa de Mestrado em Desenvolvimento Regional da UnC. Santa Catarina. Brasil. E-mail: valdirdallabrida@gmail.com

${ }^{4}$ Engenheira Agrônoma com doutorado, Pós-Doutoranda no Programa de Mestrado em Desenvolvimento Regional da UnC e Professora do IFSC-Campus Canoinhas. Santa Catarina. Brasil. E-mail: eliziane.benedetti@ifsc.edu.br
}

DRd - Desenvolvimento Regional em debate (ISSNe 2237-9029)

v. 6, n. 2, ed. esp., p. 207-227, jul. 2016. 


\section{ABSTRACT \\ THE YERBA MATE IN THE NORTH OF SANTA CATARINA STATE: THE BIOACTIVE COMPOUNDS IN MATÉ IN THE REGION AS VARIABLE IN DETERMINING THE SPECIFICS REQUIRED FOR RECOGNITION AS A GEOGRAPHICAL INDICATION}

Historically, the yerb mate (Ilex paraguariensis) has been one of the main agricultural products of southern Brazil and currently represents species of great economic, social and ecological potential. There is evidence your benefits health, through the beneficial attributed to bioactive compounds whose concentration may change depending on genetic, environmental and technological variables, including cultivation and processing. In this manner, it is expected the specifics of the subsidy may be an herbal justifiable as a way of adding value to the raw materials and natural resources development, and that can contribute to the recognition of the product as a geographical indication (GI). Characteristics of mate allow its cultivation both full sun and shade, in many cases it is recommended fertilization. The objective of this study was to evaluate the influence of light and organic fertilization on the content of caffeine and methylxanthines in yerb mate leaves, developed in herbal kills, herbal and herbal in "caíva" and in open "caíva", in municipality of Irineópolis, Santa Catarina State. It is found that the plants in lesser luminance localities had higher caffeine content, average of $12.63 \mathrm{mg} / \mathrm{g} \pm 4.59$ compared with herbal open in "caíva" $(9.46 \mathrm{mg} / \mathrm{g}$ \pm 2.05 ). The results showed that the addition of organic fertilizer, a general way increasing the content of phenolics and methylxanthines. In this way the fertilizer management should be considered for specific production of raw material, with greater or lesser content and enable the production of raw materials, according to requirements of the consumer market, and be a variable of product as GI.

Keywords: Yerb mate. Fertilization. Phenolic. Methylxanthines. Geographical Indication.

\section{INTRODUÇÃO}

Historicamente, a erva-mate tem sido um dos principais produtos agrícolas da região sul do Brasil e, atualmente, representa espécie de grande potencial econômico, social e ecológico. A erva-mate é uma planta nativa utilizada na nutrição humana, que provêm principalmente de pequenas e médias propriedades rurais dos estados do Paraná, Santa Catarina e Rio Grande do Sul (JACQUES, 2005).

Algumas características da erva-mate, possibilitam seu cultivo tanto a pleno sol quanto em sombreamento (SANTIN et al., 2015) e, sua composição fitoquímica pode ser influenciada pelo tipo de erval. De maneira geral, são classificadas em erval nativo (sombreado) e a pleno sol ou cultivado (sem cobertura vegetal). $\mathrm{O}$ erval nativo é aquele que foi formado pela ação da natureza, o qual apresenta uma característica de área semiaberta, localizado em meio a remanescentes florestais nativos (MEURER, 2012; PALACIOS, 2010).

Há indícios de diferenciação fitoquímica da erva-mate produzida em cada um dos sistemas. Por exemplo, Jacques et al. (2007) constataram que plantas cultivadas a pleno sol apresentaram menor teor de cafeína e Medrado (2004) detectou maior concentração de cafeína em folhas parcialmente sombreadas. 
Atualmente ganham importância estudos relacionando às variáveis citadas com o teor de compostos químicos buscando materiais e tecnologias direcionadas a usos alternativos da erva-mate. Características da erva-mate (nativa ou plantada) possibilitam seu cultivo tanto a pleno sol quanto em sombreamento, com ou sem algum tipo de adubação e, em sua composição fitoquímica, os teores de metilxantinas e de compostos fenólicos podem ser influenciados pelo tipo de erval.

O uso de extratos da planta e desenvolvimento de produtos com maior potencial tecnológico também vem ganhando notoriedade nos estudos da erva-mate. Antes da chegada dos europeus na América, a erva era consumida pelos nativos como uma infusão de folhas secas e esmagadas e talos moídos no preparo do chimarrão, uma bebida estimulante. Em relação ao mercado atual, há uma revalorização dos produtos naturais com aumento da demanda por produtos orgânicos, de uma forma geral. No caso específico da erva-mate, esta tendência configura ganho de valor agregado quando a matéria-prima é proveniente de ervais nativos, ou manejados por meio de adensamento, obedecendo aos princípios de sustentabilidade natural do sistema (BURTNIK, 2006).

O foco desse estudo é avaliar o impacto dos diferenciais da erva-mate nativa cultivada em diferentes níveis de luminosidade, considerando os compostos bioativos, na determinação da sua especificidade, com vistas ao reconhecimento do produto como Indicação Geográfica. Nesse sentido, será avaliado se a erva-mate da região do Planalto Norte Catarinense, produzida em diferentes sistemas de cultivo, com variáveis níveis de intensidade luminosa e adubação, terá variação nos teores de compostos fenólicos e metilxantinas.

O foco desse estudo foi avaliar o impacto dos diferenciais da erva-mate nativa cultivada em diferentes níveis de luminosidade, considerando os compostos bioativos, como variável na determinação da sua especificidade, com vistas ao reconhecimento do produto como Indicação Geográfica. Nesse sentido, será avaliado se a erva-mate da região do Planalto Norte Catarinense, produzida em diferentes sistemas de cultivo, com variáveis níveis de intensidade luminosa e adubação, terá variação nos teores de compostos fenólicos e metilxantinas 5 .

O texto está dividido em duas partes: inicialmente se apresenta a revisão bibliográfica com uma abordagem sobre desenvolvimento territorial, a indicação geográfica com ênfase na especificidade de produtos dando destaque para aspectos da erva-mate; finaliza com a apresentação e discussão dos resultados do estudo de campo e suas considerações finais.

\section{REFERENCIAL TEÓRICO}

Dentre as concepções teóricas que fundamentam a discussão sobre o tema Indicação Geográfica (IG), destacam-se abordagens que são fundamentais: a concepção de território, desenvolvimento territorial e especificidade de produto. É a partir desses conceitos, que se fundamentam as bases para a caracterização e entendimento dos fatores a serem identificados, para que possa ser realizado o processo de Indicação Geográfica.

\footnotetext{
${ }^{5}$ Esse estudo faz parte do plano de atividades do Programa de Mestrado em Desenvolvimento Regional, na forma de dissertação da autora principal, sendo os demais autores, orientadora e coorientadores.
} 


\section{TERRITÓRIO}

É perceptível que as questões territoriais vêm recebendo cada vez mais atenção nos meios acadêmicos e sociais, refletindo o interesse da sociedade pela temática. $\mathrm{O}$ conceito de território exige esforços de diversos estudiosos das mais variadas áreas e, dessa forma, a noção de território nos dias de hoje, ultrapassa os limites do campo da Geografia, sendo concebida e utilizada pela Sociologia, Ciência Política, Econômica e Antropologia.

O território nasce com uma dupla conotação, material e simbólica, pois etimologicamente surge tão próximo de terra-territorium quanto de terreo-territor (terror, aterrorizar). Ou seja, tem a ver com dominação (jurídico-política) da terra e com a inspiração do terror, do medo, especialmente para aqueles que, com essa dominação, ficam alijados da terra, ou no território são impedidos de entrar (HAESBAERT, 2007).

Autores da Geografia concordam que território é uma construção social, sendo resultado do processo de produção do e no espaço; um está no outro e ambos se efetivam pelas atividades dos homens; são sociais e resultantes de relações do poder (DALLABRIDA, 2016). Os territórios não resultam do acaso histórico. Parafraseando Saquet (2015), o território é uma construção social, histórica, relacional e está sempre vinculado a processos de apropriação e dominação do espaço. Assim, o território é compreendido como resultante da organização social, espaço humano, lugar de vida e trabalho.

$\mathrm{Na}$ concepção dos autores, alia ao entendimento de território a dimensão de poder no sentido mais concreto, que logo tem uma relação política, de denominação, de apropriação num sentido mais figurado. A formação do território configura-se pelas técnicas, objetos e coisas, pelo conjunto territorial e pela dialética do próprio espaço. Assim o território é definido pelas questões de poder, em que as relações entre indivíduos e instituições estabelecem os limites de abrangência (SAQUET; SILVA, 2008).

O território, com essa conotação, é o recorte do espaço em que ocorre a vivência da sua população, que se manifestam sua cultura e o modo de fazer, que se expressam os recursos naturais com suas paisagens, que são realizadas as atividades produtivas. Alguns territórios conseguem ressaltar a especificidade quanto ao modo de fazer determinado produto, dando-lhe notoriedade, tornando-o específico, com o que há o reconhecimento externo. Em outros casos, são as características oriundas do meio natural que dão especificidade a determinado produto. É sobre essas dimensões que vamos nos referir à especificidade territorial e à Indicação Geográfica.

\section{ESPECIFICIDADE TERRITORIAL DE PRODUTOS E SUA RELAÇÃO COM A INDICAÇÃO GEOGRÁFICA}

Algumas cidades, regiões ou territórios, ao longo de sua história, ganharam notoriedade por causa de seus produtos ou serviços. A variedade de costumes, culturas, produtos ou serviços existentes em um local caracteriza os lugares, pelos quais nos permite identificar e conhecer uma determinada região. Logo esses produtos podem ser caracterizados por possuirem especialidades resultantes da sua origem geográfica e do modo particular de produção, relacionado com os hábitos culturais da população, que caracterizam os costumes e 
tradições de um determinado grupo. É isso que atribui a alguns produtos especificidade territorial.

O tipo de ligação entre um produto ou grupo de produtos e território pode servir de base para a diferenciação de um recurso local. Um produto (recurso natural potencialmente valorizado) com forte ancoragem no território, ou características específicas estabelecidas pelo território pode ser analisado com embasamento em tal relação. Assim, a caracterização da junção entre um produto e seu território é o resultado do processo no qual os atores locais estão estabelecendo acordos sobre como e com que é obtido um produto típico local (CHAMPREDONDE, 2015).

Quando qualidade e tradição se encontram num espaço físico, a Indicação Geográfica (IG) surge como fator decisivo para garantir a diferenciação do produto e pode contribuir significativamente para sua valorização de um território ou região. Esse pode ser considerado como artifício importante de políticas de recuperação dos serviços e produtos locais. Tem como função atrelar esses produtos com as pessoas de um determinado local, potencializando e melhorando os produtos, como consequência, promovendo o desenvolvimento territorial.

Ao analisar as características típicas de produtos, nos últimos anos, a tendência à valorização do patrimônio natural tem incentivado iniciativas de preservação ambiental, no caso da região em estudo, tanto de manutenção da paisagem de araucária, como de valorização da erva-mate. A busca pela certificação ou pelo selo de produto de IG, seja esse na forma de Indicação de Procedência ou de Denominação de Origem, pode representar um diferencial competitivo no mercado (DALLABRIDA, 2012).

A Indicação Geográfica, como o próprio nome sugere, se refere a recortes territoriais reconhecidos por produtos ou serviços que tenham uma origem geográfica específica. $\mathrm{O}$ registro reconhece reputação, qualidades e características que estão vinculadas ao território. Como resultado, o produto se torna conhecido por uma característica diferenciada, por ser produzido em determinada região ou território específico. Desse modo "[...] no momento atual, em que o ambiente mercadológico valoriza produtos diferenciados, a elaboração de estratégias de desenvolvimento baseadas nas especificidades territoriais tornou-se um vetor de alto poder de agregação de valor aos produtos ou serviços” (DALLABRIDA, 2012, p. 47).

Existem duas modalidades de Indicação Geográfica: Indicação de Procedência (IP) caracterizada por ser área conhecida pela produção, extração ou fabricação de determinado produto. Está relacionado ao fato de que o território é conhecido por originar o produto em questão, sem se referir às características específicas do produto. A Denominação de Origem (DO) é uma categoria em que características daquele território agregam um diferencial ao produto, ou seja, um produto cujas qualidades sofram influência exclusiva ou essencial, decorrente das características daquele lugar, incluídos fatores naturais e humanos (DALLABRIDA et al., 2014).

Um produto típico pode ter dois significados. O primeiro significado do termo referese à propriedade peculiar de ser de um grupo, país, região, etnia, etc. O segundo significado do termo normalmente faz referência ao produto com certas características típicas. Esse último significado leva-nos a considerar as características típicas como o efeito da interação entre o território em que esse processo se desenrola, a cultura da comunidade dentro do qual 
ele evolui e a qualidade específica do produto em questão (CHAMPREDONDE, 2011). Na Figura 1, procuramos representar essa relação.

Figura 1 - Principais fatores que interagem nas características típicas de um produto

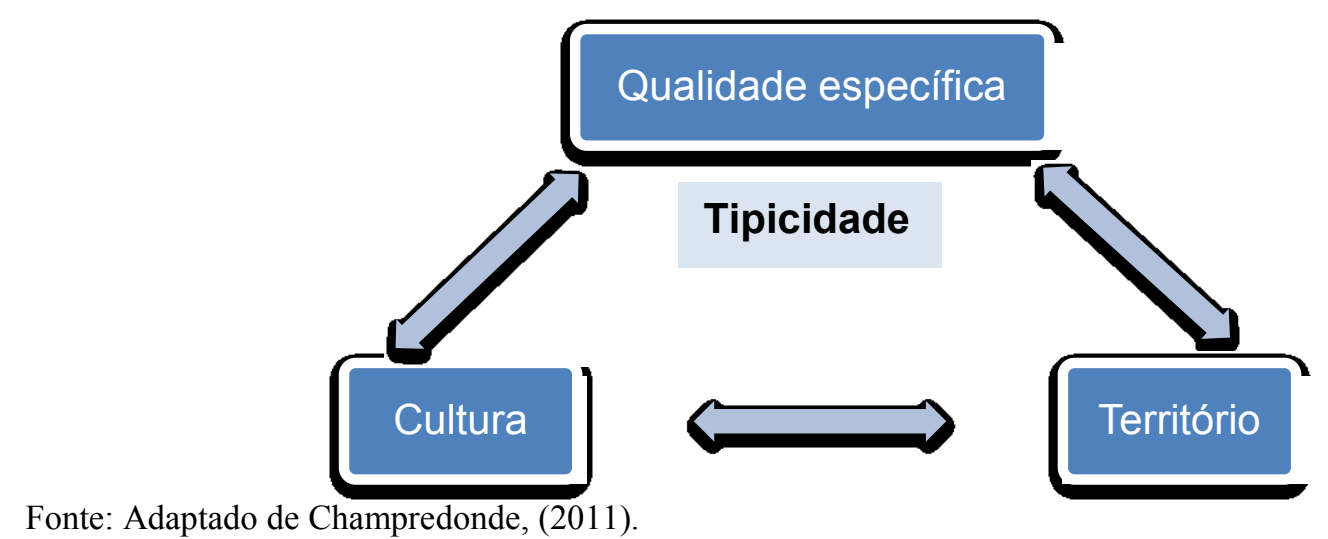

Isto é, um dado produto pode ser identificado por suas particularidades, as quais podem ser diferenciadas de produtos similares, em função da tradição e cultura local e das especificidades atribuídas pelas características socioculturais, econômicas e ambientais do território. É o que lhe atribui especificidade.

O cultivo da erva-mate é uma prática muito difundida no Sul do Brasil, em especial, no Planalto Norte Catarinense. Considerando a tradição regional em relação à erva-mate, bem como, o sistema de cultivo predominante e características ambientais, tal região ervateira é reconhecida interna e externamente por este produto, o que lhes dá a condição de reconhecimento como $\mathrm{IG}^{6}$.

A IG é uma certificação oficial atribuída a produtos gastronômicos ou agrícolas tradicionalmente produzidos numa região. No âmbito das discussões sobre desenvolvimento territorial e projetos de IG, destaca-se a perspectiva territorial, possibilidade que leva em conta a produção de produtos e serviços e a permanência dos traços históricos e culturais (MAIORKI; DALLABRIDA, 2015).

O reconhecimento de uma IG promove a participação de muitos atores. No nível local, é determinado pela organização diretamente envolvida na extração, produção, fabricação, transformação e distribuição. O elemento estruturante, tanto no processo de construção e a avaliação do pedido de reconhecimento, é a qualidade provida por estes selos de diferenciação com base na origem de procedência (CHAMPREDONDE, 2016; MAIORKI; DALLABRIDA, 2015). Diante de mercado, a IG tem possibilidade de salvaguardar as particularidades locais e regionais dos produtos, as quais são valorizadas e atestam seus níveis

\footnotetext{
${ }^{6}$ Nota do Editor: Em estudo que está relatado em artigo desta edição, o qual trata da questão da governança territorial em experiências de IG, ressalta-se que as características de especificidade encontradas no Planalto Norte Catarinense, se estendem e são contíguas à outra região do Paraná, o Centro-Sul, defendendo-se, como resultante dessa constatação, a que a IG da erva-mate abranja os dois recortes territoriais. Sabemos que isso não é um reconhecimento geral, necessitando de mais discussão regionalmente.
} 
de qualidade relacionados a fatores naturais e de intervenção humana em uma determinada área (TONIETTO, 2003).

A atividade comercial da erva-mate na região em referência tem pelo menos 152 anos, sendo um produto exportado para o mercado nacional e internacional, em especial, países do Mercosul. Na região do Planalto Norte Catarinense, a erva-mate sempre teve destaque entre os produtos agrícolas (DALLABRIDA, 2012). Dessa maneira, o debate do tema Indicação Geográfica precisa ser contextualizado entre os esforços que os atores territoriais realizam em relação à definição de seu futuro, a fim de que tal estratégia de articulação territorial seja considerada um meio e não um fim em si mesmo (DALLABRIDA et al., 2014). Diante desse contexto, a Indicação Geográfica é indicada como um fator, dentre outros, para articulação dos processos de desenvolvimento territorial.

Para que haja o reconhecimento formal da IG é preciso que o local seja claramente reconhecido pela população como região produtora daquele determinado bem ou serviço, com características especiais e com um determinado padrão de conformidade e qualidade estabelecida pelo grupo de produtores. O estímulo às pesquisas científicas é essencial na requalificação da erva-mate perante o mercado consumidor, de produto simples de baixo valor agregado, para produto com importantes propriedades funcionais e com produção ambientalmente correta. Assim, espera-se que as especificidades dos ervais locais possam ser um subsidio justificável, como forma de agregação de valor da matéria-prima e valorização dos recursos naturais, revalorizando a preservação ambiental e que possa contribuir para o desenvolvimento territorial.

\section{O DEBATE TEÓRICO SOBRE DESENVOLVIMENTO TERRITORIAL}

No senso comum o crescimento econômico é entendido, em geral, como sinônimo de desenvolvimento. Não obstante, o desenvolvimento nos remete a algo bem mais amplo do que o simples crescimento econômico. Ou seja, crescimento e desenvolvimento são termos que se confundem, no entanto, há uma distinção entre ambos.

Isso, pois, o desenvolvimento não envolve somente crescimento da economia ou apenas uma variação na produtividade; ele abrange mudanças de ordem qualitativa no modo de vida de toda uma sociedade. Assim, existência do desenvolvimento está dependente de se avaliar além do fator econômico, os fatores que podem propiciar uma melhor condição de vida em seus aspectos sociais, culturais e ambientais (DALLABRIDA, 2015). Sintetizando, o entendimento é de que, para haver desenvolvimento, as bases culturais, ambientais, sociais, econômicas e políticas, devem se manter em harmonia para que possam auxiliar, no mínimo, na promoção da equidade e justiça social e ambiental.

O desenvolvimento abrange hoje uma tripla condição: social, no sentido de acesso à educação, moradia, serviços de saúde, alimentação, uso racional e sustentável dos recursos e respeito da cultura e tradições no seu entorno social; econômica, em relação às oportunidades de emprego, satisfação, como mínimo das necessidades básicas e uma boa distribuição da riqueza; e política, a respeito da legitimidade não só em termos legais, mas também em termos de prover à maioria da população benefícios sociais e participação nas decisões (DALLABRIDA, 2010). 
Assume-se, nesse estudo, a concepção de desenvolvimento expressa em Dallabrida (2015, p. 325):

O desenvolvimento territorial é entendido como um processo de mudança continuada, situado histórica e territorialmente, mas integrado em dinâmicas intraterritoriais, supraterritoriais e globais, sustentado na potenciação dos recursos e ativos (materiais e imateriais, genéricos e específicos) existentes no local, com vistas à dinamização socioeconómica e à melhoria da qualidade de vida da sua população.

O desenvolvimento territorial em algumas definições é caracterizado como resultante de um processo de construção, por um determinado grupo social inserido num atividade produtiva, enraizada num espaço geográfico. Reafirmando essa compreensão, Pecqueur (2005, p. 12) resume que "[...] o desenvolvimento territorial não pode ser implantado por decreto; permanece uma construção dos atores, mesmo que políticas públicas apropriadas possam estimular e mobilizar esses atores". Essa construção, portanto, é, também, inserida no tempo.

Esse entendimento perpassa ao encontro da proposta de estudo, em que os ativos dos fragmentos da Floresta Ombrófila Mista podem servir de recursos e ativos de desenvolvimento territorial. Por meio desses recursos florestais e serviços prestados pelas florestas, poderá haver influência positiva no processo econômico e consequentemente social e ambiental, contribuindo com o processo de recuperação e/ou preservação da paisagem que o compõem.

Na procura de melhorias para o desenvolvimento territorial, a discussão maior a ser caracterizada pela pesquisa será na dimensão ambiental, tornando-a um critério primordial para a busca do aproveitamento do patrimônio natural. Nesse contexto, são de fundamental importância os fragmentos florestais nativos e os seus manejos, em destaque para a erva-mate, respeitando-se os preceitos da sustentabilidade.

\section{A ERVA-MATE}

Os primeiros a fazerem uso da erva-mate foram os índios Guaranis, que habitavam a região definida pelas bacias dos rios Paraná, Paraguai e Uruguai, na época da chegada dos colonizadores espanhóis. Da metade do século XVI até 1.632 a extração da erva-mate era a atividade econômica mais importante da Província Del Guairá, território que abrangia praticamente o Paraná, e no qual foram fundadas 3 cidades espanholas e 15 reduções jesuíticas (BERKAI; BRAGA, 2000).

A partir dos anos 1970 a fabricação e a transformação da erva-mate nas diversas regiões produtoras passaram por profundas mudanças. A formação que era em sua totalidade, derivada da exploração de ervais nativos, tem ampliado aos poucos a participação de ervais cultivados. Com isso, diferentes tipos de erva-mate eram elaborados $\mathrm{e}$ as diferenças verificadas estiveram ligadas à região e aos processos de trabalho e de geração do produto (SOUZA, 2003).

A caracterização da erva-mate pode ser feita de acordo com o tipo de erval. Tradicionalmente existe o erval nativo, sombreado e o cultivado, sem cobertura vegetal. $\mathrm{O}$ erval nativo é aquele formado naturalmente, situado em meio à floresta. $\mathrm{O}$ erval cultivado é 
caracterizado pelo plantio de mudas e um sistema de manejo convencional (MEURER, 2012). A erva-mate tolera plantio a pleno sol, podendo ser plantada sozinha ou em sistemas agroflorestais (ROSSA, 2013).

"A erva-mate possui significativa importância econômica e social para grande parte da região sul do Brasil”" (MARQUES; DENARDIN; REIS, 2014, p. 33), essa espécie é “[...] nativa da Floresta Ombrófila Mista, e seu cultivo pode favorecer a valorização econômica da floresta, promovendo-a como um ativo ambiental" (BRASIL, 2012, p. 122). A expansão do mercado da erva-mate pode ser uma alternativa para proprietários de terras em áreas da Floresta Ombrófila Mista, o que incentiva a recomposição de áreas degradadas, as pastagens, por exemplo, com cultivos da erva-mate em sistemas agroflorestais. Apresenta grande importância nos sistemas de produção dos agricultores familiares, conferindo valor monetário para a floresta em pé, o que contribui para a conservação dos remanescentes florestais (BRASIL, 2012; MARQUES et al., 2014).

É uma das principais riquezas naturais da região do Planalto Norte Catarinense e Centro-Sul do Paraná. Para Gerhardt (2013) a planta é caracterizada, do ponto de vista da Biologia e da Botânica, pela complexidade. Ela é percebida nas formas de reprodução vegetal e de interação com outras espécies que compõem o também complexo ecossistema florestal. Isso tornou a erva-mate uma planta de grande interesse para as populações que conviveram com ela e para a ciência.

\section{Caracterização da Espécie}

A erva-mate (Ilex paraguariensis St. Hil.), pertencente à família botânica Aquifoliaceae, classificada em 1822 pelo botânico francês August de Sain Hilaire, quando da coleta em região nos arredores de Curitiba no Estado do Paraná. Possui mais de 700 espécies, dessas 60 ocorrem no Brasil, e cinco delas são beneficiadas para o consumo. Antes da chegada dos europeus na América, a erva-mate era consumida pelos nativos como uma infusão de folhas secas e esmagadas e talos moídos no preparo do chimarrão, uma bebida estimulante. Nos dias de hoje, mate, erva-mate ou yerba-mate são as denominações populares dadas à planta, bem como ao produto constituído pelas suas folhas e talos (LOPES, 2011).

Os consumidores principais da erva-mate são pessoas físicas, que compram para o chimarrão ou o chá, no preparo caseiro. As funções de propriedades químicas do mate, como ação antioxidante e estimulante, são ainda pouco exploradas pela indústria ervateira, fazendo com que esses atributos não sejam percebidos como diferenciais do produto (BRASIL, 2012). Além dos atributos já conhecidos, podem-se vislumbrar muitos aproveitamentos potenciais da planta, os quais poderiam vir a expandir seu consumo e, consequentemente, aumentar o mercado para essa matéria-prima (ESMELINDRO et al., 2002).

Importância Socioeconômica da Erva-Mate

O agronegócio da erva-mate é expressivo no sul do Brasil, com aproximadamente 663 mil pessoas envolvidas com essa atividade, e em torno de 110 mil propriedades agrícolas que se dedicam à sua produção (KREUZ; SOUZA; STADLER, 2005). A área de distribuição 
natural da erva-mate, abrange, aproximadamente, $540.000 \mathrm{~km}^{2}$, cerca de $3 \%$ do território da América do Sul, compreendendo áreas do Brasil, Argentina e Paraguai, situadas entre as latitudes de $21^{\circ} \mathrm{S}$ a $30^{\circ} \mathrm{S}$ e longitudes de $48^{\circ}$ a $56^{\circ} \mathrm{W}$ (Figura 2) (ROSSA, 2013).

Figura 2 - Área de ocorrência natural da Erva-Mate (Ilex paraguariensis).

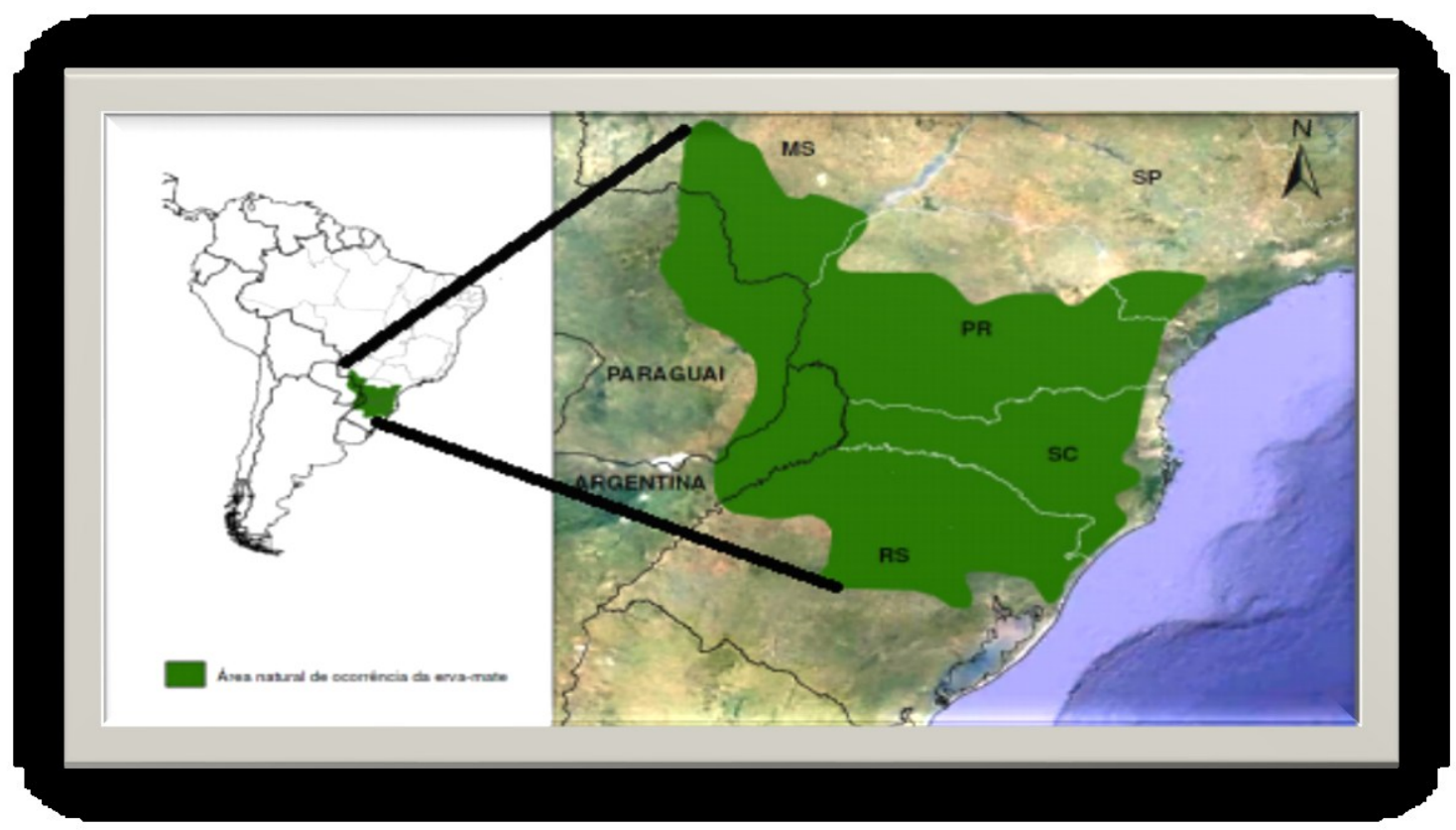

Fonte: Rossa (2013, p. 23).

Estudos tem mostrado que a erva-mate tem sido significativamente mais rentável nas pequenas propriedades do que os produtos agrícolas mais comuns como a soja, milho, feijão, trigo e de que os plantios florestais comuns atualmente nas pequenas e médias propriedades do sul do Brasil, tais como, o pinus e o eucalipto (MEDRADO; MOSELE, 2004).

\section{Composição Foliar da Erva-Mate}

A erva-mate é uma espécie economicamente importante nos países do cone sul. Porém, a deficiência de dados sobre o teor de compostos químicos influencia na condição e qualidade dos seus produtos comerciais. A estrutura da planta de erva-mate responde diretamente às condições ambientais, como intensidade luminosa e teores de nutrientes, podendo alterar sua morfologia e seus processos fisiológicos (MAZUCHOVSKI, 2001).

As condições ambientais são fatores que afetam a biossíntese na interface química entre as plantas e o ambiente circulante, as quantidades de compostos bioativos podem variar por inúmeros fatores (Figura 3), como, a sazonalidade, temperatura, disponibilidade hídrica e de nutrientes, radiação ultravioleta, ritmo circadiano, poluição, entre outros (SILVA, 2012). 


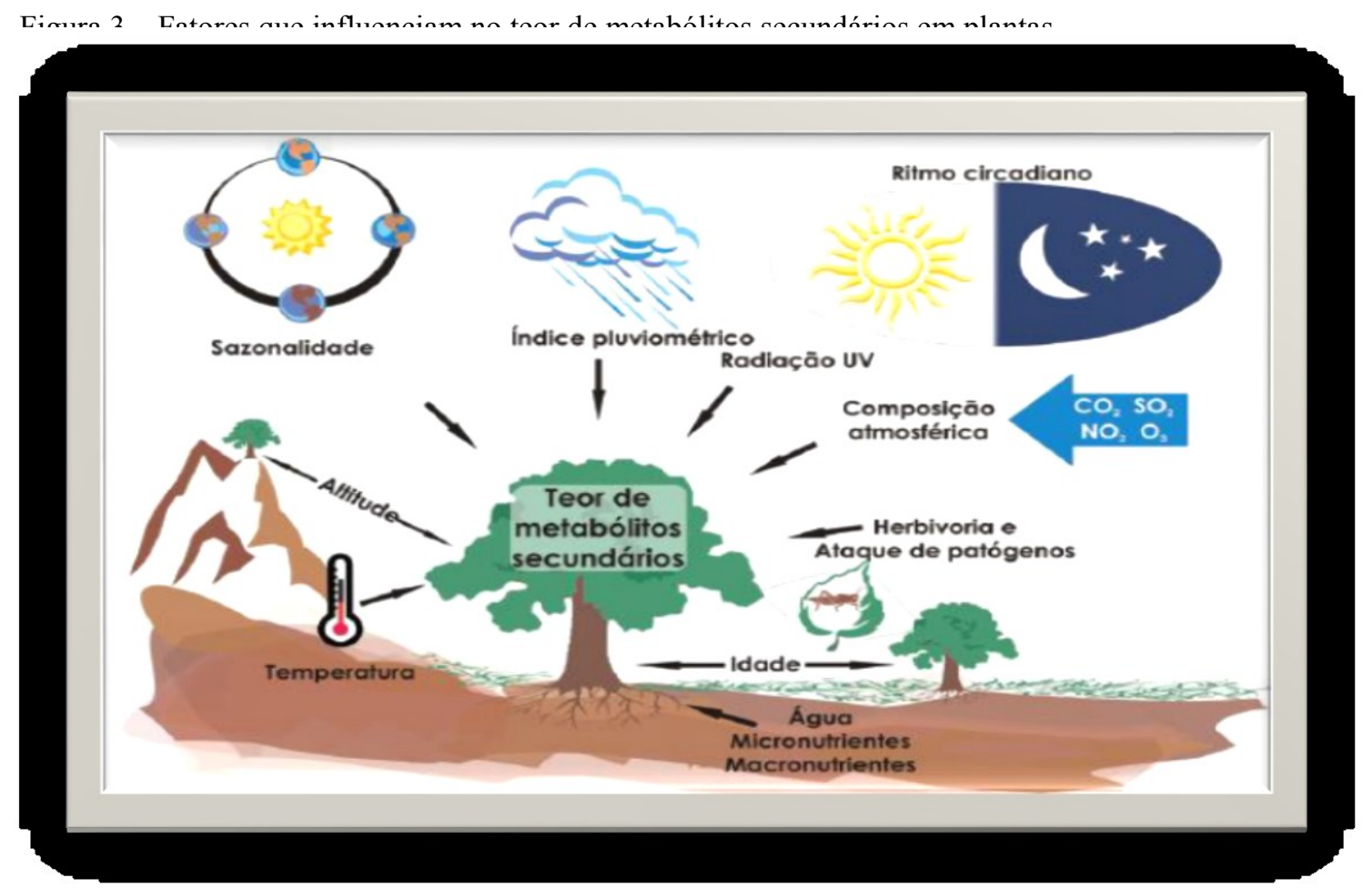

Fonte: Silva (2012)

A luz é um dos mais importantes fatores abióticos que afeta a fisiologia e a morfologia dos vegetais. Os ajustes morfofisiológicos que acontecem nas plantas são relacionados principalmente com a manutenção da eficiência do balanço entre o ganho de carbono, pela fotossíntese, e a perda de água, pela transpiração, consequentemente, as folhas desenvolvem características estruturais para otimizar esse processo, o que reflete na produção de massa verde das plantas (GIVNISH, 1988; SMITH et al., 1997; TAIZ; ZEIGER, 2004; VOGELMANN et al., 1996). Os efeitos da luz sobre o crescimento das plantas dependem de sua intensidade, qualidade espectral ou comprimento de onda e duração ou periodicidade, a variação em qualquer dessas características pode modificar o crescimento, quer quantitativamente quer qualitativamente (LARCHER, 1986).

A erva-mate tem demonstrado características químicas diversas, a depender da espécie, idade da árvore e das folhas, clima, tempo de colheita, sistema de cultivo e solo (MAZZAFERA, 1994; ESMELINDRO et al., 2002). Dentre os compostos químicos citam-se as metilxantinas, saponinas, taninos, minerais, vitaminas, substâncias aromáticas, ácidos graxos, terpenos, álcoois, aldeídos, além de açúcares (JACQUES, 2005; MEURER, 2012).

Os compostos fitoquímicos, principalmente os compostos fenólicos, saponinas e metilxantinas, estão associados ao sabor, odor, cor e estabilidade oxidativa dos alimentos. Assim sendo, o chá mate pode apresentar diferenças significativas em suas características sensoriais, especialmente no seu sabor amargo e adstringente, devido a modificações na composição química de matérias-primas como polifenóis e cafeína com resultado econômico direto sobre o preço de mercado. Assim, é possível prever que o teor de compostos farmacologicamente ativos, polifenóis e alcaloides, também varia ao longo das colheitas (MAZZAFERA, 1994) e entre os sistemas de cultivo, devido à influência das variáveis de campo e de gestão agronômica (COELHO et al., 2007). 
$\mathrm{Na}$ determinação de compostos em folhas de erva-mate, com 18 meses, em condição de sombra (75\% de luminosidade retida) e pleno sol, Jacques et.al., (2007) constataram que plantas cultivadas a pleno sol apresentaram menor concentração de cafeína, ácido palmítico, fitol e vitamina, ao passo que maior intensidade luminosa aumentou a concentração de ácido esteárico e esqualeno. Mazzafera (1994) também observou maiores concentrações de cafeína em folhas parcialmente sombreadas. Porém, segundo Andrade (2004), o maior teor foliar de cafeína em mudas de erva-mate ocorre nos extremos máximos de luz e sombra.

A correlação positiva entre intensidade luminosa e a produção de compostos bioativos fenólicos, em destaque os flavonoides, já foi apresentada por Silva (2012). As plantas designadas como cultivadas em pleno sol se caracterizam por possuir incidência maior de radiação solar direta, identificadas como plantas cultivadas em monoculturas. E as plantas cultivadas em sombra são aquelas com menor incidência de radiação solar direta, caracterizadas como plantas de sistema florestal ou mista (SERAFIM, 2013).

É uma planta caracteristicamente encontrada em ambientes sombreados, crescendo espontaneamente em sub-bosques de pinhais, principalmente em Floresta Ombrófila Mista. Com ocorrência de Araucaria angustifolia, tolera bem o sombreamento natural, o que a caracteriza também como planta reprodutora à sombra, sendo ela cultivada fora de suas condições naturais, podem ocorrer alterações fisiológicas no sentido de sua adaptação ao meio (BRASIL, 2012; MARQUES, 2014).

\section{PROCEDIMENTOS METODOLÓGICOS}

O estudo foi desenvolvido no município de Irineópolis-SC, em uma propriedade rural, que apresentava ervais nativos nas seguintes condições: (i) Erval em mata (cobertura florestal mais conservada, erval nativo, sem a presença constante de animais); (ii) Erval em caíva (cobertura florestal relativamente conservada, erval nativo, presença constante de animais, sub-bosque com presença de pastagens) e (iii) Erval em Caíva Aberta (cobertura florestal mais aberta pela ação antrópica, erval nativo, presença constante de animais, sub-bosque dominado pelas pastagens na maior parte da área) (MARQUES, 2014). Em cada tipo de erval, selecionaram-se seis plantas, das quais três receberam adubação orgânica e três não receberam adubação (controles).

Para o suprimento dos nutrientes utilizou-se a cama de frango que é um adubo orgânico disponível facilmente na região. A partir da análise do solo e da necessidade de fósforo para cultura da erva-mate determinou-se a dose da cama de frango. A adubação foi parcelada em duas aplicações (efetuadas em setembro de 2015 e janeiro de 2016) em superfície ao redor da planta. As plantas adubadas também receberam uma dose de calcário para suprir cálcio e magnésio, conforme recomendação para a cultura da erva-mate (SANTIN; BENEDETTI e REISSMANN, 2015). Após três meses da última adubação realizou-se a coleta das folhas de galhos da brotação do ano, colhidos no terço médio da copa para posterior determinação de cafeína e metilxantinas. Após a separação do galho da folha, as folhas foram secas a $65^{\circ} \mathrm{C}$ em estufa com ventilação de ar por $10 \mathrm{~h}$ aproximadamente. Depois de seco, o material foi triturado em moinho do tipo Willey até obtenção de pó, e em seguida peneirado em tamiz de malha $1,5 \mathrm{~mm}$, ficando acondicionadas em saco plástico até o preparo dos extratos para as análises fitoquímicas. 


\section{EXTRAÇÃO DE METILXANTINAS E DETERMINAÇÃO DOS TEORES}

Foram preparados extratos aquosos contendo $5 \mathrm{~g}$ de pó de folhas, $100 \mathrm{ml}$ de solução de ácido sulfúrico a $20 \%(\mathrm{v} / \mathrm{v})$ para cada amostra. O processo extrativo foi baseado no descrito por Shubert et al. (2006). Brevemente, depois da ebulição em banho-maria por $10 \mathrm{~min}$, os extratos foram filtrados em papel filtro e neutralizados com solução de hidróxido de amônia a $25 \%$ e extraídos em 3 porções de $10 \mathrm{ml}$ de mistura de clorofórmio: isopropanol (3:1 v/v), ajustado o volume para $75 \mathrm{ml}$. A fração orgânica foi dessecada em sulfato de sódio anidro e filtrada para a determinação do rendimento de extrato de metilxantinas totais.

A determinação dos teores de metilxantinas totais foi realizada por método espectrofotométrico em espectrofotômetro por ultravioleta (UV) (Bel Spectro-Lgs53), em comprimento de onda de $273 \mathrm{~nm}$, utilizando-se a cafeína como substância de referência. Para a curva de calibração foram preparadas soluções hidroalcóolicas $\left(\mathrm{EtOH}: \mathrm{H}_{2} \mathrm{O}\right.$ 4:6 v/v) com concentrações de 2,$0 ; 4,0 ; 8,0 ; 10,0 ; 16,0 ;$ e $20,0 \mu \mathrm{g} / \mathrm{mL}$. Cada solução foi lida em triplicata, sendo calculada a média para cada ponto da curva. As médias foram plotadas em gráfico de concentração versus absorbância, calculando-se o coeficiente de regressão linear e a equação da reta correspondente pelo método dos mínimos quadrados.

\section{EXTRAÇÃO DOS FENÓLICOS E DETERMINAÇÃO DOS TEORES}

Foram preparados extratos das amostras de folhas de erva-mate por infusão aquosa de cinco gramas de pó em $100 \mathrm{ml}$ de água destilada $\left(90^{\circ} \mathrm{C}\right)$ por $20 \mathrm{~min}$. Os extratos foram filtrados, os volumes ajustados para $100 \mathrm{ml}$ com água destilada. A determinação dos teores de fenólicos totais (TFT) foi de acordo com Medina (2011 a, b), a qual foi baseada na interação direta entre polifenóis com o sal de diazônio Fast Blue BB. Foram preparadas sete soluções aquosas de ácido clorogênico com concentrações padrão, na faixa de $10-150 \mu \mathrm{g} / \mathrm{mL}$ e a cada uma foram adicionadas $0,2 \mathrm{~mL}$ do reagente a $0,1 \%$. As soluções foram homogeneizadas por 1 min e à reação foram acrescentados $0,2 \mathrm{ml}$ de $\mathrm{NaOH} \mathrm{5 \%}$. Depois de $90 \mathrm{~min}$ em temperatura ambiente as absorbâncias foram medidas a $420 \mathrm{~nm}$ em espectrofotômetro por UV. Os resultados foram expressos como miligramas equivalentes de ácido clorogênico por grama de extrato após regressões lineares aplicando a média a partir das concentrações resultantes para cada três plantas com ou sem adubação, identificadas por tipos de ervais. Os coeficientes de correlação obtidos foram $\mathrm{R}^{2}=0,9994$ para cafeína $\mathrm{R}^{2}=0,9501$ para fenólicos.

\section{RESULTADOS E DISCUSSÃO}

De acordo com os resultados, foi observado que os constituintes bioativos pesquisados apresentaram resultados muito variáveis, inclusive entre as plantas de um mesmo tipo de erval. Nas plantas analisadas os teores de metilxantinas variaram de 10,75 a $107,10 \mathrm{mg} / \mathrm{g}$ e para os compostos fenólicos a variação foi de 12,8 a 144,65 mg/g.

As metilxantinas são constituintes químicos importantes de várias bebidas $\mathrm{e}$ estimulantes não alcoólicos, como café, guaraná, cola e chocolates, sejam como preparações caseiras ou produtos industrializados, com grande importância econômica e cultural. As mais 
abundantes são a cafeína, a teofilina e a teobromina. Na erva-mate a maior proporção é de cafeína (JACQUES, 2005; MEURER, 2012).

Os compostos fenólicos têm sido estudados em diversas plantas por participarem dos processos responsáveis pela cor, adstringência e aroma, e ser um importante elemento de defesa das plantas. Na erva-mate, os compostos fenólicos são percebidos pelo sabor amargo da bebida (FILIP et al., 2001; PAGLIOSA et al.; 2008), característica almejada por vários mercados consumidores.

A inúmera prática silviculturais utilizada no manejo dos ervais tem sido considerada como algumas das responsáveis pelos resultados contraditórios nos estudos envolvendo sua composição e teores de bioativos. Dentre esses fatores, inclui-se a luminosidade, o tipo de erval e a presença ou não de práticas de adubação.

A Tabela 1 ilustra, a média e desvio padrão do teor de fenólicos e metilxantinas das plantas avaliadas na propriedade rural, divididas em erval na mata (sombreada), erval em caíva (luminosidade intermediária) e erval em caíva aberta (maior incidência de luz), sendo todos ervais nativos.

Tabela 1 - Teor de fenólicos e cafeína nos diferentes ambientes e adubações

\begin{tabular}{|c|c|c|c|}
\hline \multicolumn{4}{|c|}{ Fenólicos mg/g* } \\
\hline & Erval em mata & Erval em caíva & Erval em caíva aberta \\
\hline Sem adubação & $35,39 \pm 13,20$ & $21,42 \pm 2,87$ & $28,82 \pm 7,87$ \\
\hline Com adubação & $24,87 \pm 12,82$ & $73,22 \pm 14,48$ & $103,85 \pm 33,90$ \\
\hline \multicolumn{4}{|c|}{ Cafeína $\mathrm{mg} / \mathrm{g} *$} \\
\hline & Erval em mata & Erval em caíva & Erval em caíva aberta \\
\hline Sem adubação & $7,05 \pm 0,66$ & $12,63 \pm 4,59$ & $9,46 \pm 2,05$ \\
\hline Com adubação & $16,68 \pm 1,57$ & $36,89 \pm 6,09$ & $13,01 \pm 1,15$ \\
\hline
\end{tabular}

Streit et al. (2007) apontaram resultados em que as plantas em locais de menor luminosidade apresentaram os maiores teores de cafeína. No presente estudo essa caraterística não ficou evidenciada, pois em erval na mata, os teores médios de cafeína foram de $7,05 \mathrm{mg} / \mathrm{g}$ e no erval em caíva, foi identificado um teor maior desse bioativo nas plantas, com média de $12,63 \mathrm{mg} / \mathrm{g}$. Os resultados demostram que, igualmente ao que ocorreu com o teor de metilxantinas (cafeína), houve grande variabilidade no teor de compostos fenólicos nas plantas.

Para o item luminosidade, é indicado haver uma correlação positiva com a variação no teor de compostos fenólicos (RACHWAL et al., 2000) e foi possível observar que tanto para o grupo de plantas mais sombreadas quanto para aquelas com menor luminosidade ocorreram variações de até três vezes no teor de fenólicos totais.

Para a erva-mate é comum haverem variações importantes nos teores de cafeína e compostos fenólicos, conforme indicações constantes na Tabela 2. 
Tabela 2- Dados de teores de cafeína e fenólicos $(\mathrm{mg} / \mathrm{g})$ em folhas de erva-mate

\begin{tabular}{|c|c|c|}
\hline Teor de Cafeína (mg/g) & Teor de Fenólicos (mg/g) & Autor \\
\hline 5,4 & - & Mazzafera (1997) \\
\hline 6,5 & - & Reginatto et al.(1999) ${ }^{2}$ \\
\hline 7,2 & - & Zampier $(2001)^{2}$ \\
\hline 13,1 & - & Esmelindro et al. $(2002)^{3}$ \\
\hline 6,4 & - & Cardozo Junior et al. (2003) ${ }^{1}$ \\
\hline 19,5 & - & Borille, Reissmann, Freitas $(2005)^{3}$ \\
\hline 16,6 & - & Rakocevic et al. $(2006)^{2}$ \\
\hline & 7,73 & Bastos et al. $(2007)^{2}$ \\
\hline 7,05 & - & Streit et al. $(2007)^{2}$ \\
\hline 15,03 & - & Santin $(2008)^{1}$ \\
\hline 46,79 & 279,49 & Meurer (2012) \\
\hline & 235,30 & Blum-Silva et al. $(2015)^{2}$ \\
\hline 95,72 & 287,58 & Presente Estudo $^{3}$ \\
\hline
\end{tabular}

Método de Análise: ${ }^{1}$ Cromatografia líquida, ${ }^{2}$ Cromatografia líquida de alta eficiência ${ }^{3}$ e Espectrofotômetro UV.

Fonte: Dados da Pesquisa (2016)

O Gráfico 1 demonstra que nos três tipos de ervais, com ou sem adubação, o teor de fenólicos observado numericamente foi sempre superior ao de metilxantinas. Nas amostras de erva-mate nos três sistemas de sombreamento, as plantas com adubação apresentaram teor desses compostos maiores que nos tratamentos sem adubação. A importância desses resultados está no fato de que essas variações podem alterar o sabor do produto e abrem a possibilidade de poderem ser destinados a segmentos específicos do mercado, ampliando, dessa forma, as alternativas de comercialização pelos produtores.

Gráfico 1 - Teor de fenólicos e cafeína nos diferentes ambientes e adubações

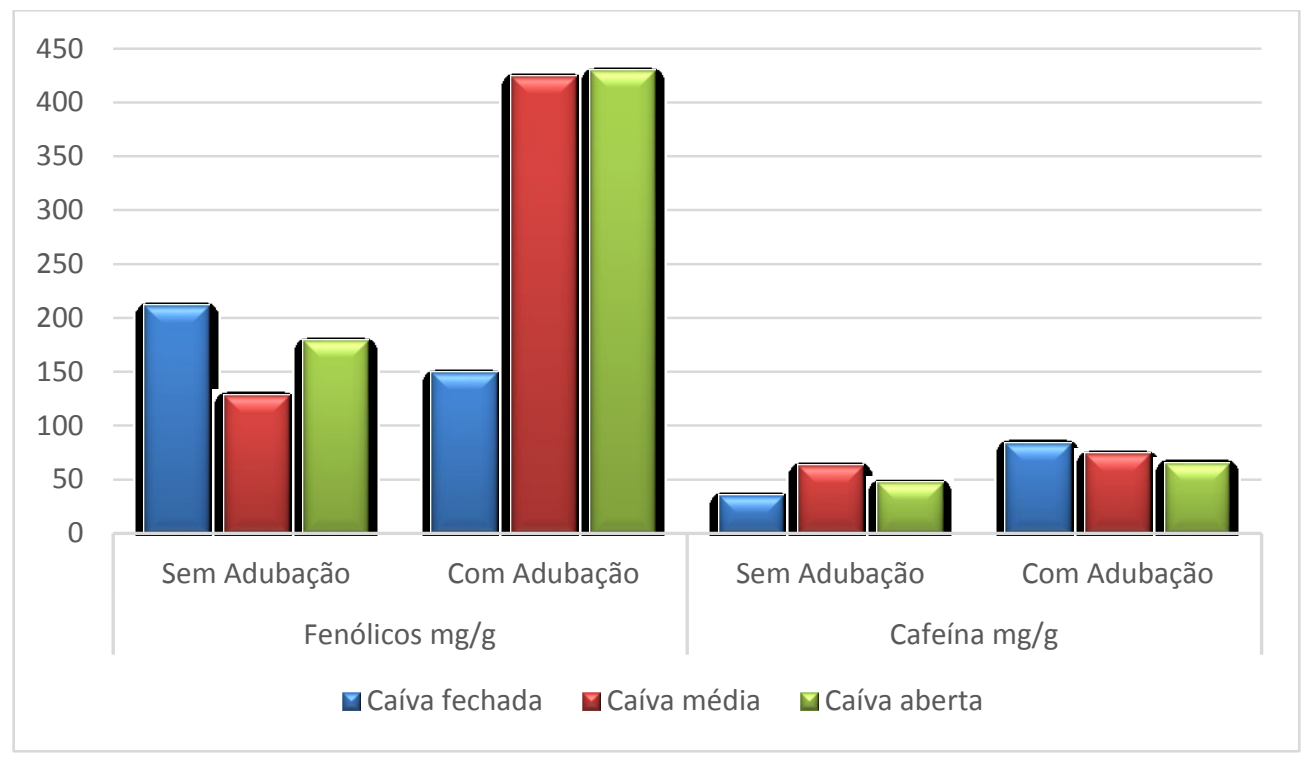

Fonte: Dados da pesquisa (2016)

Relativo às diferenças observadas nas plantas que receberam a adubação orgânica, como a cafeína é formada por moléculas de nitrogênio (RATES, 2004), o maior teor 
observado nas plantas adubadas, provavelmente está relacionado ao nitrogênio que havia na composição do adubo usado. Essa observação de melhoria nos teores de cafeína pode possibilitar a obtenção de matéria-prima com maior ou menor teor de cafeína, por meio do manejo de adubação (Gráfico 1). No entanto, não se pode deixar de registrar que o fator genética da planta tem grande influência como sugerem Donaduzzi et al. (2003), sobre as características das plantas e pode ser responsável por grande parte dos resultados obtidos.

A qualidade da erva-mate da região do Planalto Norte Catarinense vem do fato de serem extraídos de ervais sombreados, localizados em Floresta Ombrófila Mista, chamados de ervais nativos Além disso, a exploração comercial dos ervais nativos em áreas de floresta contribui para a manutenção da biodiversidade local (LOPES, 2011).

A região do Planalto Norte Catarinense é reconhecida ela qualidade de sua erva-mate, de onde sai a matéria-prima para o chimarrão e outras bebidas. A diferença encontrada entre os tipos de ervais justificaria a notoriedade da região por seus produtos oriundos dos ervais nativos, uma vez que a composição química da planta interfere diretamente no produto gerado a partir dela (STREIT, et al.; 2007; PAGLIOSA et al., 2008) e possibilita o desenvolvimento de uma identidade regional para erva-mate dos ervais nativos da região do Planalto Norte Catarinense.

\section{CONSIDERAÇÕES FINAIS}

Os resultados da pesquisa mostraram que a intensidade luminosa em condições naturais alterou os teores de metilxantinas (cafeína) e fenólicos em extratos aquosos produzidos de folhas dos indivíduos de uma população de erva-mate. Adicionalmente, a quantidade de substâncias ativas nas folhas interfere também na qualidade dos produtos comerciais gerados a partir da erva-mate. O sabor é uma função da composição química e pode ser modificado pelo teor de compostos fenólicos e metilxantinas na planta. As condições de cultivo e a época da coleta, na medida em que podem alterar a composição e a concentração de substâncias presentes na planta, podem influenciar as características da matéria-prima e esses fatores podem desempenhar papel relevante na qualidade da erva-mate.

Como a adição de adubação, de maneira geral, aumentou os teores de fenólicos e cafeína, o manejo de adubação deve ser considerado para produção de matéria-prima específica, com maior ou menor teor, a fim de atender à exigência do mercado consumidor. A técnica de adubação orgânica demonstrou-se positiva para a produção de erva-mate nativa em caívas, uma vez que aumentou a biossíntese das metilxantinas e fenólicos, o que pode possibilitar a produção de matéria-prima diferenciada, conforme exigências do mercado consumidor, demonstrando-se como uma variável para IG.

Os resultados obtidos neste trabalho sugerem, além da avaliação dos parâmetros utilizados neste estudo, o uso de outras técnicas de medição para melhor controle dos níveis de sombreamento a que estão expostas as plantas de erva-mate. Como complementação da análise química, poderiam ser realizados testes sensoriais, procurando relações entre a composição química e o sabor. O mesmo tipo de estudo também poderia ser feito em outras épocas do ano, para avaliação dos compostos secundários em diferentes condições climáticas e as diferenças de progênies. São desafios para novos estudos. 


\section{REFERÊNCIAS}

ANDRADE. F. M. de. Avaliação de biomassa, clorofila, cafeína e tanino em Ilex paraguariensis Saint-Hilaire, crescendo sob sombreamento e pleno sol. UFPR, 2004. $83 \mathrm{f}$. Dissertação (Mestrado em Ciências Florestais) - Universidade Federal do Paraná, Curitiba, 2004.

BASTOS, D. H. M.; et al.; Phenolic Antioxidants Identified by ESI-MS from Yerba Maté (Ilex paraguariensis) and Green Tea (Camelia sinensis) Extracts. Molecules, v. 12, p. 423432, 2007.

BORILLE, A. M. W.; REISSMANN, C. B.; DE FREITAS, R. J. S. Relação entre compostos fitoquímicos e o nitrogênio em morfotipos de erva-mate (Ilex paraguariensis St.Hil.).

Boletim CEPPA, Curitiba, v. 23, n. 1, p.183-198, 2005.

BRASIL. Análise integrada das cadeias produtivas de espécies nativas da floresta ombrófila mista e seu impacto sobre esse ecossistema. Fundação Centros de Referência em Tecnologias Inovadoras. Grupo Boticário de Proteção a Natureza. Relatório final: Diagnóstico das cadeias produtivas do pinhão e da erva-mate, Curitiba, v. 1.I, fev. p. 2-182, 2012.

BERKAI, D.; BRAGA, C. A. 500 anos de história da erva-mate. Porto Alegre: Cone Sul, 2000.

BURTNIK, O. J. Yerba Mate: Manual de Producción. INTA, AER Santo Tomé, Corrientes, Argentina, p. 52, 2006.

CARDOZO JUNIOR, E. L. et al. Variação no teor de cafeína em dezesseis progênies de ervamate (Ilex paraguariensis St. Hil.) cultivadas em três municípios do Paraná. In:

CONGRESSO SUL-AMERICANO DA ERVA-MATE, 3., 2003, Chapecó. Anais. Chapecó: Ed. News Print, 2003. 1 CD-ROM.

CHAMPREDONDE, M. A. Qué es un producto típico certificable mediante IG/ DO en el contexto Latinoamericano? Exemplos a partir de casos argentinos. Perspectivas Rurales. Nueva época. Argentina: INTA, Ano 10, n. 19, p. 61- 82, 2011.

. Tipicidad territorial: elemento fundacional de la construcción de una denominación de origen. DRd - Desenvolvimento Regional em Debate. v. 6, n. 1, jan./jul. p. 22-40, 2016.

; BORBA, M. F. S. B. Diferenciar productos locales contribuyendo al desarrollo territorial. Montevideo: IICA, p. 64, 2015.

DALLABRIDA, V.R. Desenvolvimento regional: porque algumas regiões se desenvolvem e outras não? Santa Cruz do Sul: EDUNISC, 2010.

Território e desenvolvimento sustentável: indicação geográfica da erva-mate de ervais nativos no Brasil. Toledo, v. 16, n. 1, p.42-59, 2012. 
. Governança Territorial: do debate teórico à avaliação da sua prática. Análise Social, v. 2, p. 304-328, 2015.

Ativos territoriais, estratégias de desenvolvimento e governança territorial: uma análise comparada de experiências brasileiras e portuguesas. EURE, v. 42, n. 126, maio. p. 187-212, 2016.

et al. Indicação geográfica da erva-mate no território do contestado: reflexões e

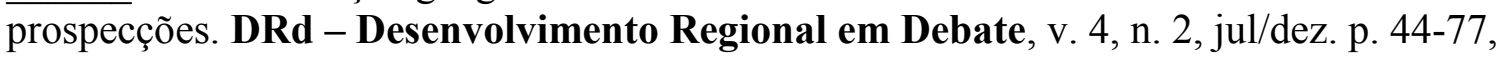
2014.

DONADUZZI, C. M.; JUNIOR, E. L. C.; DONADUZZI, E. M., SILVA, M. M.; J. A.; CORREA, G. Variação nos teores de polifenóis totais e taninos em dezesseis progênies de erva-mate (Ilex paraguariensis St. Hill.) cultivadas em três municípios do Paraná. Arquivo Ciência Saúde Unipar, v. 7, p. 129-134, 2003.

ESMELINDRO, M. C. et al. Caracterização físico-química da erva-mate: influência das etapas do processamento industrial. Ciência Tecnologia Alimentos de Campinas, São Paulo, v. 22, n. 2, maio/ago. p. 199-204, 2002.

GERHARDT, M. História Ambiental da Erva-Mate. Florianópolis: UFSC, 2013, 290 f. Tese (Doutorado em História) - Programa de Pós-Graduação em História, Centro de Filosofias e Ciências Humanas, Universidade Federal de Santa Catarina, Florianópolis, 2013.

GIVNISH, T. J. Adaptation to sun and shade: a whole-plant perspective. Australian Journal of Plant Physiology, Melbourne, v. 15, p. 63-92, 1988.

HAESBAERT, R. C. Território e multiterritorialidade: um debate. GEOgrafia, a. 9, v. 7, n.17, p. 19-46, 2007.

JACQUES, R. A.; Caracterização química da erva-mate (Ilex paraguariensis): aplicação de diferentes processos de extração e influência das condições de plantio sobre a composição química. UFRGS, 2005, 137f. Tese (Doutorado em Química) Programa de Pós-Graduação em Química, Instituto de Química, Universidade Federal do Rio Grande do Sul, Porto Alegre, 2005.

JACQUES, R. A. et al. Journal of agricultural and food chemistry. Influence of agronomic variables on the macronutrient and micronutrient contents and thermal behavior of mate tea leaves (Ilex paraguariensis). Journal of agricultural and food chemistry, Easton, v. 55, n. 18, p. 7510-7516, 2007.

LARCHER, W. Ecofisiologia Vegetal. São Paulo: Editora Pedagógica e Universitária, 2004.

LOPES, N. O. V. E. A indicação geográfica como forma de valorização da biodiversidade no Planalto Norte Catarinense. UFSC, 2011, 164f. Dissertação (Mestrado em Agroecossistemas) Programa de Mestrado em Agroecossistemas, Centro de Ciências Agrárias, Universidade Federal de Santa Catarina, Florianópolis, 2011. 
MAIORKI, G.; DALLABRIDA, V. R.; A Indicação Geográfica De Produtos: Um Estudo Sobre sua Contribuição Econômica no Desenvolvimento Territorial. Interações, Campo Grande, v. 16, n. 1, jan./jun, p. 13-2, 2015.

MARQUES, A.; DENARDIN, V.F.; REIS, M.S. As paisagens dos ervais no planalto norte catarinense e a conservação dos remanescentes florestais. Agriculturas, v. 11, n. 3, out, p. 3236, 2014. Acesso em: http://www.agriculturesnetwork.org/magazines/brazil/paisagenscamponesas/planalto-norte-catarinense. Acesso em: 26 jul. 2015.

MARQUES, A. C. As paisagens do mate e a conservação socioambiental: um estudo junto aos agricultores familiares do planalto norte catarinense. UFPR, 2014. $434 \mathrm{f}$. Tese (Doutorado em Meio Ambiente e Desenvolvimento), Universidade Federal do Paraná, Curitiba, 2014.

MAZZAFERA, P. Caffeine, theobromine and theophylline distribution in Ilex paraguariensis. Braz. J. Plant Physiol. v. 6, p. 149-151. 1994.

MAZUCHOWSKI, J. Z. Incorporação e exportação de biomassa e de nutrientes pela erva-mate. UFPR - EMATER, Paraná. 28 p. Curitiba, 2001.

MEDINA, M. B. Determination of the total phenolics in juices and superfruits by a novel chemical method. Journal of Functional Foods, v.3, p.79-87, 2011 a.

Simple and rapid method for the analysis of phenolic compounds in beverages and grains. Journal of Agricultural and Food Chemistry, v. 59, p. 1565-1571, 2011 b.

MEDRADO, M. J. S.; MOSELE, S. H. O futuro da investigação cientifica em erva-mate. Embrapa. Colombo, Paraná, 2004.

MEURER, A. Z. Caracterização química e climática de populações naturais de ervamate (Ilex paraguariensis) no Planalto Norte Catarinense. Dissertação (Mestrado) Programa de Pós-Graduação em Recursos Genéticos Vegetais, UFSC, Florianópolis, 2012.

PAGLIOSA, C. M. et al. Bitterness in yerba mate (Ilex paraguariensis) leaves. Journal of Sensory Studies. Vol. 24, p. 415-426, 2008.

PALACIOS, P. I. C. Sistemas de cultiva de erva-mate: atributos físicos, indicadores de qualidade e estoque de carbono num latossolo vermelho aluminoférrico. UFPR, 2010, $91 \mathrm{f}$. Dissertação (Mestrado em Ciência do Solo) Programa de Pós-Graduação em Ciências do Solo, Setor de Ciências Agrárias, Universidade Federal do Paraná, Curitiba, 2010.

PECQUEUR, B. O desenvolvimento territorial: uma nova abordagem dos processos de desenvolvimento para as economias do sul. Raízes, Florianópolis, v. 24, n.1-2, p. 10-22, 2005.

RACHWAL, M.F.G.; CURCIO, G.R.; DEDECEK, R.A.; NIETSCHE, K.; RADOMSKI, M.I. Influência da luminosidade sobre os teores de macronutrients e tanino em folhas de ervamate. In: Congresso Sul-Americano da Erva-Mate. 2. Reunião Técnica da Erva-Mate. 3. Encantado/RS: Edição dos Organizadores, 19-23, nov. 2000. Anais... p. 417-420, nov. 2000.

DRd - Desenvolvimento Regional em debate (ISSNe 2237-9029) 
RAKOCEVIC, M. et al. Influência do sexo, da sombra e da idade das folhas no sabor do chimarrão. In: Congreso sudamericano 4; reunión técnica 4 e exposición de agronegocios de la yerba mate 2. Posadas, 2006. Actas... Posadas, Misiones, p. 31-36, 2006.

REGINATTO, F. H.; ATHAYDE, M. I.; GOSMANN, G.; SCHENKEL, E. P.

Methyxanthines accumulation in Ilex species - caffeine and theobromine in ervamate (Ilex paraguariensis) and other Ilex species. Journal Brazilian Chemical Society, São Paulo, v. 10, n. 6, p. 443-446, 1999.

ROSSA, U. B. Produtividade e compostos foliares de erva-mate sob efeitos de luminosidade e fertilização. UFPR, 2013, 208f. Tese (Doutorado em Engenharia Florestal). Programa de Pós-Graduação em Engenharia Florestal, Universidade Federal do Paraná, Curitiba, 2013.

SAQUET, M. A.; SILVA, S. S.; Milton Santos: concepções de geografia, espaço e território. Geo UERJ - Ano 10, v. 2, n.18, p. 24-42, $2^{\circ}$ semestre de 2008.

. Por uma Geografia das Territorialidades e das Temporalidades. Uma concepção multidimensional voltada para a cooperação e para o desenvolvimento territorial. Rio de Janeiro: Consequencia, 2015.

SANTIN, D.; BENEDETTI, E. L.; REISSMANN, C. B. Nutrição e recomendação de adubação e calcário para a cultura da erva-mate. In: WENDLING, I.; SANTIN, D. Propagação e nutrição de erva-mate. Brasília, DF: Embrapa, 2015, p. 99-195.

SILVA, C. H.; Influência da Idade das Folhas e da Luminosidade nos Teores de Metilxantinas, Ácido Clorogênico, Fenólicos Totais e na Atividade de Captação de Radicais Livres de Extratos Aquosos de Ilex Paraguariensis A. St. Hilaire. UFSC, 2012, 92f. Dissertação (Mestrado) Programa de Pós-Graduação em Farmácia. Universidade Federal de Santa Catarina, Florianópolis, 2012.

SMITH, W. K. et al. Leaf form and Photosynthesis: do leaf structure and orientation interact to regulate internal light and carbon dioxide? Bioscience, Washington, DC, v. 47, n. 11, p. 785-793, 1997.

SOUZA, A. M.; FOSSATI, L. C.; KREUZ, C. L. Possibilidades De Revalorização dos Tradicionais Processos de Produção e de Transformação de Erva-Mate no Planalto Norte Catarinense. Congresso Sul-americano da erva-mate, v.3, 2003. Resumos. Chapecó, SC, 16 a 19/nov, 2003. 137 p.

STREIT, N. A. et al. Relation among taste-related compounds (phenolics and caffeine) and sensory profile of erva-mate (Ilex paraguariensis). Elsevier, v. 102, p. 560-564, 2007.

TAIZ, L.; ZEIGER, E. Fisiologia Vegetal. 3. ed. Porto Alegre: Artmed, 2004. 719 p.

VOGELMANN, et al. Leaves and light capture: light propagation and gradients of carbon fixation within leaves. Trends in Plant Science, Oxford, v. 1, n. 2, p. 65-70, 1996. 
ZAMPIER, A.C.; Avaliação dos níveis de nutrientes, cafeína e taninos após adubação mineral e orgânica, e sua relação com a produtividade na erva-mate (illex paraguariensis St Hil.) UFPR, 2001, 114f. Dissertação (Mestrado) Programa de Mestrado em Engenharia Florestal. Área de Sivicultura, Universidade Federal do Paraná, Curitiba, 2001.

Artigo recebido em: 23/06/2016

Artigo aprovado em: 14/07/2016 